\title{
Breast Cancer Survival in the Mammography Era in Brazil: A Population-Based Analysis of 2,715 Cases
}

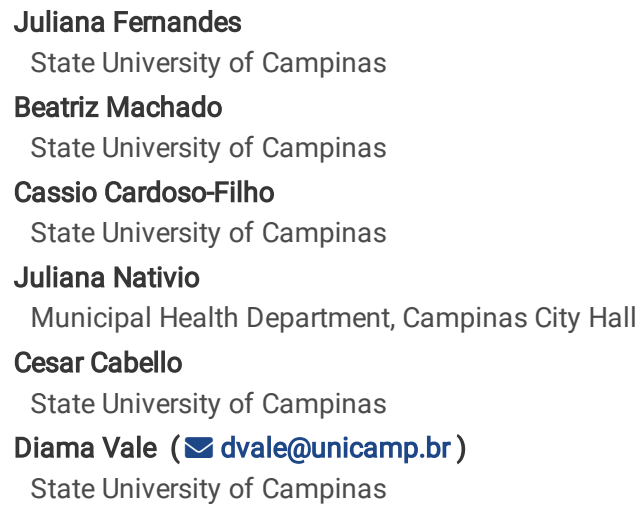

Research Article

Keywords: Breast Neoplasms, Survival Analysis, Neoplasm Staging, Early Detection of Cancer, Mortality

Posted Date: June 18th, 2021

DOI: https://doi.org/10.21203/rs.3.rs-625485/v1

License: (c) (1) This work is licensed under a Creative Commons Attribution 4.0 International License. Read Full License 


\section{Abstract}

Background This study aims to assess breast cancer survival rates after one decade of mammography in a large urban area of Brazil.

Methods It is a population-based retrospective cohort of women with breast cancer in Campinas, São Paulo, from 2010 to 2014 . Age, vital status and stage were accessed through the cancer and mortality registry, and patients records. Statistics used Kaplan-Meier, log-rank and Cox's regression.

Results Out of the 2,715 cases, 665 deaths (24.5\%) were confirmed until early 2020 . The mean age at diagnosis was 58.6 years. Women $50-69$ years were $48.0 \%$, and stage I the most frequent (25.0\%). The overall mean survival was 8.4 years (8.2-8.5). The 5-year survival (5yOS) for overall, 40-49, 50-59, 60-69, 7079 years was respectively $80.5 \%, 87.7 \%, 83.7 \%, 83.8 \%$ and $75.5 \%$. The 5 yOS for stages $0, \mathrm{I}, \mathrm{II}$, III and IV was $95.2 \%, 92.6 \%, 89.4 \%, 71.1 \%$ and $47.1 \%$. There was no significant difference in survival in stage I or II ( $p=0.058)$. Compared to women $50-59$ years, death's risk was 2.3 times higher for women $70-79$ years and $26 \%$ lower for women 40-49 years. Concerning stage I, the risk of death was 1.5, 4.1 and 8.6 times higher, and $34 \%$ lower, respectively, for stage II, III, IV and 0.

Conclusions In Brazil, breast cancers are currently diagnosed in the early stages, although advanced cases persist. Survival rates may reflect improvements in screening, early detection and treatment. The results can reflect the current status of other regions or countries with similar health care conditions.

\section{Background}

Breast cancer is a significant public health problem, being one of the leading causes of mortality and morbidity that affects the female population between 40 and 69 years old [1]. When diagnosed at early stages, it has great chances of cure. In selected countries, survival rates can reach $90 \%$ in five years [2]. Since the number of breast cancer survivors has increased, survival analysis describes disease behaviour and related prognostic factors.

The elements that stand out the most in the prognosis of women with breast cancer are age at diagnosis, size of the tumour, staging, therapeutic management, delays in treatment, race and socioeconomic status [3]. At the early stages, treatments are less aggressive, and morbidities lower, resulting in higher survivals [4]. The five-year survival rates in stages I and II (early breast cancer - E.B.C.) range from 80-99\%, while in a more advanced stage with metastasis (stage IV), the survival rate may drop to less than $30 \%$ [5]. Barriers to accessing screening are challenges women face in low- and middle-income countries to have an early diagnosis. Limited access to therapeutic modalities may also lead to reduced survivals, regardless of the stage [2, 6].

Breast cancer is most frequently diagnosed in women in the post-menopausal period, between 55 and 64 years old [5]. About $20 \%$ occur in women below this age-group. These cases tend to present more aggressive tumours, with a greater chance of developing resistance to treatment, therefore lowering survival rates $[7,8]$.

Survival rates vary somewhat around the world. In the U.S.A., the five-year survival rate is 90\% (2010-2016), and in England 85\% (2013-2017) [5, 9]. In Latin American and Central American countries in general, this rate is around $80 \%$ [2]. Brazil's last population-based survival rate reported figures of $74.3 \%$ from 2000 to 2014 [10]. The scarcity of quality data in low and middle-income countries makes it challenging to implement public cancer control policies.

Adequate data to calculate cancer incidence and survival rates come from population-based cancer registries (P.B.C.R.). Campinas has a P.B.C.R. integrating the database of the National Cancer Institute [11]. It is an urban city with 1.2 million inhabitants, presenting social inequalities similar to those observed in other large cities of middle-income countries [12]. According to age and stage at diagnosis, this study aims to assess the overall survival of breast cancer rates in Campinas, based on data from the P.B.C.R. from 2010 to 2014. This period reflects one decade of mammography spread in the region for screening and early detection of cancer. The results of this study can guide policymakers to improve health care for this and other similar areas.

\section{Methods}

It was a retrospective cohort study of women diagnosed with breast cancer in Campinas between 2010 and 2014. The P.B.C.R. includes all cancer cases of women living in the city, regardless of the type of health assistance provided (public or private). After excluding duplicates and cases registered by death certificates, 2,715 cases were last in the database. The original P.B.C.R. and the Mortality Information System (M.I.S.) records were the sources of primary data. When data were lack, patient's records from the municipality's health services were accessed. Women were diagnosed by public or private services in the city. Only Campinas residents are included in the P.B.C.R.

To be defined as 'deaths', cases should be registered as such in the databases. The remaining cases were considered 'alive'. Of those alive, $15 \%$ were accessed through records on the region's hospitals or clinics and censored on the last registered follow-up date. The remaining were considered alive until March 31, 2020, when the COVID-19 pandemic spread in Brazil and the isolation period started. Around this date, $37,5 \%$ of these women had an active financial transaction record (Individual Taxpayer Register - C.P.F., available for public consultation).

The following variables were available and included for analysis: age at the date of diagnosis, vital status, date of death, date of censorship/last follow-up, and stage at diagnosis - according to the American Joint Committee on Cancer [13]. Crossing information through systems and the different records accessed enable to correct misrecording data at the P.B.C.R.

Overall survival was calculated by the time from the date of diagnosis (histopathologic result) until the date of death or until the study's censorship or end date. Statistics was performed by the Kaplan-Meier method and expressed as percentages. The log-rank test compared the different survival curves of the different categories of variables. Cox's regression models were applied to assess factors related to survival and to estimate risk ratios. For statistical analysis, the computer program S.A.S. for Windows (Statistical Analysis System), version 9.2, was employed. (S.A.S. Institute Inc, 2002-2008, Cary, NC, U.S.A.). 
This study is part of a regular research project funded by F.A.P.E.S.P. under number 2017/21908-1, and was approved by the Unicamp Research and Ethics Committee under number CAAE 89399018.2.0000.5404. The funder had no involvement in the study apart of supporting financially. The Committee waived the need for Informed Consent. The confidentiality was guaranteed, and personal data was handled only by the P.B.C.R. and Mortality Surveillance Department teams as part of their routine activities. Two researchers from the study team had actively collected data in hospitals and clinics (J.F.O., B.F.M.).

\section{Results}

Of the 2,715 cases recorded between 2010 and 2014, 665 deaths (24.5\%) were confirmed until March 31, 2020. From the total sample, in 2,054 women $(75.7 \%)$, it was possible to determine the stage at diagnosis: 1,547 in the group of alive women (75.5\%) and 507 in the group of dead women (76.2\%) ( $\mathrm{p}=$ 0.685). The mean age at diagnosis was 58.6 years (median 58.0, standard deviation - SD 12.97), being 56.9 years among the alive and 64.0 years among the dead $(P<0.001)$. Women between 50 and 69 represented $48.0 \%$ of the sample, and those under $5028.5 \%$ (Fig. 1).

In women in whom it was possible to determine the stage at diagnosis, stage I was the most frequent (25.0\%) (Fig. 2). Stage 0 (in situ) corresponded to $15.4 \%$ and stage IV to $19.9 \%$. The comparison between women known and unknown stage showed an average age for those staged of 57.7 years (median 57.0 , SD 13.7) and for that not-staged of 61.6 years (median 61.0, SD 15.2) $(p<0.001)$. The median survival of women staged was 6.3 years (median 6.6, SD 2.62) and that of women not-staged of 6.5 years (median 6.9, SD 2.6) $(p=0.027)$ (data not shown).

The overall mean survival (mOS) of the sample was 8.4 years (95\% Confidence Interval - $\mathrm{Cl} 8.2-8.5$ ), the overall 5-year survival (5y0S) $80.5 \%$ and the overall 10-year survival (10yOS) $69.9 \%$. The highest mOS was in women aged 40 to 49 years ( 9.1 years; $95 \% \mathrm{Cl} 8.9-9.3$ ), and the shortest in the older group - women over 80 years ( 5.7 years; $95 \% \mathrm{Cl} 5.2-6.2$ ). The 5 yOS in women younger than 40 years was $82.2 \%$, significantly lower than for women aged 40 to $49,87.7 \%$ ( $p=$ 0.002). Up from 50 to 69 , 5yOS decreased with increasing age: $83.7 \%$ for those aged 50 to 59 years and $83.8 \%$ for those aged 60 to 69 years, $75.5 \%$ for those aged 70 to 79 and $51.4 \%$ for women older than 79 years. Table 1 shows the mOS, 5yOS and 10yOS for the different age groups.

Table 1

Overall survival of 2,715 women with breast cancer according to the age-

\begin{tabular}{|c|c|c|c|}
\hline Age (years) & $\begin{array}{l}\text { Mean } \\
\text { Overall Survival } \\
(95 \% \mathrm{Cl})\end{array}$ & $\begin{array}{l}\text { Five-years } \\
\text { Overall Survival } \\
\text { (S.D.) }\end{array}$ & $\begin{array}{l}\text { Ten-years } \\
\text { Overall Survival } \\
\text { (SD) }\end{array}$ \\
\hline$<40$ & 8.5 years $(8.1-8.9)$ & $82.2 \%(2.5 \%)$ & $68.7 \%(5.9 \%)$ \\
\hline 40 to 49 & 9.1 years $(8.9-9.3)$ & $87.7 \%(1.4 \%)$ & $82.1 \%(2.4 \%)$ \\
\hline 50 to 59 & 8.7 years $(8.5-9.0)$ & $83.7 \%(1.4 \%)$ & $78.6 \%(2.5 \%)$ \\
\hline 60 to 69 & 8.6 years $(8.3 ; 8.9)$ & $83.8 \%(1.5 \%)$ & $71.3 \%(3.6 \%)$ \\
\hline 70 to 79 & 7.6 years $(7.3-7.9)$ & $75.5 \%(2.1 \%)$ & $55.2 \%(4.1 \%)$ \\
\hline$\geq 80$ & 5.7 years $(5.2-6.2)$ & $51.4 \%(3.4 \%)$ & $34.0 \%(4.8 \%)$ \\
\hline
\end{tabular}

The 5yOS for stages 0 (in situ), I, II, III and IV was 95.2\%, 92.6\%, 89.4\%, 71.1\% and 47.1\% (Table 2). Pairwise Comparisons (Log Rank, Mantel-Cox tests) showed a significant difference in survival of stage 0 (in situ) and all others. There was no significant difference in the survival of women diagnosed with early-stage breast cancer (E.B.C., stage I or II) $(\mathrm{P}=0.058)$. The Kaplan-Meyer curves are seen in Fig. 3.

Table 2

Overall survival of 2,054 women with breast cancer according to the stage at diagnosis.

\begin{tabular}{|llll|}
\hline Stage & Mean Overall Survival $(\mathbf{9 5 \%} \mathrm{Cl})$ & $\begin{array}{l}\text { Five-years } \\
\text { Overall Survival (S.D.) }\end{array}$ & $\begin{array}{l}\text { Ten-years } \\
\text { Overall Survival (SD) }\end{array}$ \\
\hline Stage 0 (in situ) & 9.7 years $(9.5-9.9)$ & $95.2 \%(1.2 \%)$ & $91.8 \%(1.8 \%)$ \\
\hline Stage I & 9.5 years $(9.3-9.6)$ & $92.6 \%(1.2 \%)$ & $81.9 \%(4.4 \%)$ \\
\hline Stage II & 9.1 years $(8.9-9.4)$ & $89.4 \%(1.4 \%)$ & $79.8 \%(2.8 \%)$ \\
\hline Stage III & 7.6 years $(7.2-8.0)$ & $71.1 \%(2.6 \%)$ & $49.0 \%(8.3 \%)$ \\
\hline Stage IV & 5.4 years $(5.0-5.8)$ & $47.1 \%(2.5 \%)$ & $36.8 \%(3.3 \%)$ \\
\hline 95\% Cl: $95 \%$ Confidence Interval; S.D. - Standard Deviation. & \\
\hline
\end{tabular}

Univariate and multivariate analysis were performed to check the influence of age and stage (Table 3). Compared to women between 50 and 59 years old, the multivariate analysis obtained a risk of death 2.3 times and 4.2 times higher, respectively, for women 70 to 79 years old and women more aged than 79 years. For women 40 to 49 years, the risk was $26 \%$ lower. Concerning stage I, the risk of death was $1.5,4.1,8.6,2.1$ times higher and $34 \%$ lower, respectively, for women with stage II, III, IV, unknown and 0 (in situ). 
Table 3

Uni and multivariate COX regression analysis of survival in women with breast cancer $(n=2,715)$.

\begin{tabular}{|c|c|c|c|c|c|c|}
\hline \multirow[b]{2}{*}{ Age (y) } & \multicolumn{3}{|c|}{ Univariate Analysis } & \multicolumn{3}{|c|}{ Multivariate Analysis } \\
\hline & P-value & HR & $95 \% \mathrm{Cl} \mathrm{HR}$ & P-value & HR & 95\% Cl HR \\
\hline$<40$ & 0.111 & 1.29 & $0.94-1.78$ & 0.339 & 1.17 & $0.85-1.61$ \\
\hline 40 to 49 & 0.037 & 0.74 & $0.56-0.98$ & 0.033 & 0.74 & $0.56-0.98$ \\
\hline 50 to 59 & - & 1.00 & - & - & 1.00 & - \\
\hline 60 to 69 & 0.273 & 1.15 & $0.90-1.46$ & 0.127 & 1.21 & $0.95-1.54$ \\
\hline 70 to 79 & $<0.001$ & 2.02 & $1.59-2.56$ & $<0.001$ & 2.27 & $1.79-2.88$ \\
\hline \multirow[t]{2}{*}{$\geq 80$} & $<0.001$ & 4.09 & $3.20-5.22$ & $<0.001$ & 4.16 & $3.24-5.33$ \\
\hline & \multicolumn{3}{|c|}{ Univariate Analysis } & \multicolumn{3}{|c|}{ Multivariate Analysis } \\
\hline Stage & P-value & HR & $95 \% \mathrm{Cl} \mathrm{HR}$ & P-value & HR & 95\% Cl HR \\
\hline Stage 0 & 0.049 & 0.61 & $0.37-0.99$ & 0.101 & 0.66 & $0.41-1.08$ \\
\hline Stage I & - & 1.00 & - & - & 1.00 & - \\
\hline Stage II & 0.057 & 1.39 & $0.99-1.96$ & 0.016 & 1.53 & $1.08-2.15$ \\
\hline Stage III & $<0.001$ & 3.72 & $2.70-5.12$ & $<0.001$ & 4.05 & $2.94-5.59$ \\
\hline Stage IV & $<0.001$ & 8.00 & $5.99-10.68$ & $<0.001$ & 8.57 & $6.41-11.45$ \\
\hline Unknown & $<0.001$ & 2.29 & $1.69-3.10$ & $<0.001$ & 2.08 & $1.54-2.82$ \\
\hline
\end{tabular}

\section{Discussion}

In this population-based study that accessed data from 2,715 women with breast cancer in a large city in Brazil, it was observed that the average age of women at diagnosis was 58.6 years, that the diagnoses were early and that the five years overall survival (5yOS) was $80.5 \%$. Survival was significantly lower in more advanced stages and older women. It is the largest Brazilian cohort of survival assessment of the last ten years, just after the period when mammography has significantly spread in Brazil.

The universal health care system in Brazil has expanded significantly over the past decade, increasing the provision of services and cancer care qualification. Particularly in São Paulo State, mammography has been established to screen and early detection of breast cancer [14]. A significant increase in mammography access was observed in the region through national cancer control program incentives [15]. The expansion of the chemotherapy offer and the inclusion of new drugs allowed the transition to less radical treatment modalities, with less morbidity, besides being more effective.

Two results were expected in the implementation of these actions: downstaging and improvements in survival. In this study, we observed that one in every four women with breast cancer in Campinas was diagnosed in clinical stage I. A hospital-based cancer registry study of São Paulo state observed a significant upward trend in the proportion of cases diagnosed in stage I and a significant reduction in stage II cases from 2000 to 2015 [16]. This detection of tumours in earlier stages is firmly attributed to expanding the screening and early detection incentives.

In this study, the 5yOS in stages I and II were $92.6 \%$ and $89.4 \%$, respectively $(p=0.058)$, which means that the survival of radiologically or clinically detected cancers were. It is an argument to do not support screening. However, it is possible that the morbidity related to the earlier treatment would result in a better quality of life for the survivors. Another interesting result is that women diagnosed in stage 0 (in situ) corresponded to $15.4 \%$ of cases, the upper limit recommended for a screening program [17], indicating overuse and possible overdiagnosis.

The observed 5yOS was $80.5 \%$, and the ten years overall survival (10yOS) $69.9 \%$. A population-based study in Barretos, $350 \mathrm{~km}$ far from Campinas, reported a slightly lower 5yOS of $74.3 \%$ from 2000 to 2015 ( $n=2,110$ cases) [10]. Considering both cities' health care framework are relatively similar, these results are likely to indicate improved treatment assistance in the region. The large global survival surveillance consortium, the CONCORD study, updated its third version pointing to a 5yOS for Brazil of 73.9-76.5\% from 2000 to 2014, a period less sensitive to reflect the recent improvements observed in recent years [2].

This $5 y 0 S$ of $80.5 \%$ is lower than that found in high-income countries but higher than low and middle-income countries. It is challenging to consider the differences in the periods of observation $[2,18]$. From the public health perspective, this result indicates that Brazil's path in terms of investments resulted in a positive impact. Still, the sustainability of these actions is necessary to maintain the achievements. Age, stage and treatment are the factors that most influence the woman's prognosis. It should be noted that, even though there is a tendency for downstaging in Brazil, the proportion of cases diagnosed in advanced stages is still high [16].

In the multivariate analysis, compared to women in stage I, the risk of death was $34 \%$ lower for women in stage 0 (in situ), and $1.5,4.1,8.6$ and 2.1 times higher, respectively for women in stages II, III, IV and unknown. The 5yOS for stages 0 , I, II, III and IV was respectively $95.2 \%, 92.6 \%, 89.4 \%, 71.1 \%$ and 47.1 . These survivals are close to those observed in other national studies $[10,19,20]$ and lower than those found in countries like U.S.A. and England [5, 9]. 
The highest mean and 5yOS were found in the group of women aged 40 to 49 years ( 9.1 years; $95 \%$ Cl 8.9-9.3, 87.7\%), reducing significantly after 50 years. The multivariate analysis obtained a risk of death 2.3 and 4.2 times higher, respectively, for women between 70 to 79 years old and older than 79 years old; and $26 \%$ lower for those between 40 to 49 years old, compared to women between 50 to 59 years old. These results support the evidence that older women have a worse prognosis regardless of the stage at which they are diagnosed $[5,19]$. However, very young women (those under 40 years old) had a $5 y 0 S$ of $82.2 \%$, significantly less than women aged 40 to $49,87.7 \%(p=0.002)$. Other studies also point to reduced survival in very young women [7, 8,20$]$, probably due to the diagnosis of more aggressive molecular types of tumours found in this group.

This study is the largest population-based cohort published in Brazil in recent years and has benefited from the multiple data sources for its progress. Its results reflect the reality of Brazil's most populated cities, with different access and quality of care, and can guide public policies for cancer control. The current study's solidness dwells on the number of patients and the reliability of the follow-up. The active search of vital status allowed us to reach higher quality to the data presented.

There are two main limitations. The first is that in $25 \%$ of cases the stage was unknown. Secondary analyzes of these cases were carried out, and it was observed that the mean age and mean survival were slightly higher among those not staged $(p<0.001$ and $P=0.027$, respectively). It may indicate that if it had any influence on the results, it would be discreet.

The second limitation is that in $85 \%$ of the cases considered alive, it was impossible to establish the date of censorship. It may have significantly influenced the results of 10yOS and, less significantly, 5yOS an mOS. However, this is a problem inherent in population-based studies. It must be said that death records in São Paulo state are of high quality and that the analysis of the registers of women's economic activities may have mitigated this bias. We consider that given the lack of population-based studies in low and middle-income countries, the data presented is relevant even with its limitation. Its quality should be carefully evaluated compared with data from countries with well-established registration systems.

\section{Conclusions}

In Brazil breast cancer cases are currently diagnosed in the early stages, although advanced cases persist. Survival rates are lower than those observed in high-income countries but may reflect screening, early detection, and treatment improvements.

\section{Abbreviations}

5yOS - Overall 5-year survival; 10yOS - Ooverall 10-year survival; CPF

Individual Taxpayer Register; EBC - Early breast cancer (stage I or II); mOS - Overall mean survival; MIS - Mortality Information System; PBCR - Populationbased cancer registries.

\section{Declarations}

\section{Ethics approval and Consent to participate}

This study was approved by the Unicamp Research and Ethics Committee, registered at 'Plataforma Brasil' under the number CAAE 89399018.2.0000.5404. The procedures used in this study adhere to the tenets of the Declaration of Helsinki.

Due to the study's retrospective nature, the Unicamp Research and Ethics Committee waived the need for the consent form.

\section{Consent for publication}

Authors consent to the publication of the content to the publisher.

\section{Availability of data and material}

The datasets generated during the current study are available from the corresponding author on reasonable request. The Surveillance Section of the Municipal Health Department, Campinas, is the data manager and has specif restrictions to preserve confidentiality, although aggregate data may be shared upon request.

\section{Competing interests}

None to declare. The study sponsors had no involvement in the study other than funding.

\section{Funding}

This study was performed during the tenure of the research funding of the "Fundação de Amparo à Pesquisa do Estado de São Paulo (FAPESP)", registered under the number 2017/21908-1. The study sponsors had no involvement in the study other than funding.

\section{Authors' contributions}

DBV was in charge of Conceptualization, Formal analysis, Funding acquisition, Investigation, Methodology, Project administration, Supervision and Writing of the original draft. JOF contributed to Data curation, Formal analysis, Investigation and Writing of the original draft. BFM contributed to Data curation, Investigation and Writing of the original draft. CCF contributed as co-supervisor and in the Conceptualization and Methodology. JN is the head of the PBCR 
and contributed to Data curation and Validation. CC contributed to Data curation and Validation. All authors participated in the Visualization and Writing, review \& editing.

\section{Acknowledgements}

The authors would like to thanks the statistician Mr Helymar Machado and all the Surveillance Section of the Campinas Municipal Health Department personnel for their support.

\section{References}

\section{References}

1. Bray F, Ferlay J, Soerjomataram I, Siegel RL, Torre LA, Jemal A. Global cancer statistics 2018: GLOBOCAN estimates of incidence and mortality worldwide for 36 cancers in 185 countries. CA Cancer J Clin. 2018;68:394-424.

2. Allemani C, Matsuda T, Di Carlo V, Harewood R, Matz M, Nikšić M, et al. Global surveillance of trends in cancer survival 2000-14 (CONCORD-3): analysis of individual records for 37513025 patients diagnosed with one of 18 cancers from 322 population-based registries in 71 countries. Lancet. 2018;391:1023-75.

3. Ayala ALM, Anjos JCD, Cassol GA, Höfelmann DA. [Survival rate of 10 years among women with breast cancer: a historic cohort from 2000-2014]. Cien Saude Colet. 2019;24:1537-50.

4. Sant M, Allemani C, Capocaccia R, Hakulinen T, Aareleid T, Coebergh JW, et al. Stage at diagnosis is a key explanation of differences in breast cancer survival across Europe. Int J Cancer. 2003;106:416-22.

5. National Cancer Institute. Cancer of the Breast (Female) - Cancer Stat Facts. SEER. https://seer.cancer.gov/statfacts/html/breast.html. Accessed 12 Jan 2021.

6. Bray F, Jemal A, Grey N, Ferlay J, Forman D. Global cancer transitions according to the Human Development Index (2008-2030): a population-based study. The lancet oncology. 2012;13:790-801.

7. Yoshida M, Shimizu C, Fukutomi T, Tsuda H, Kinoshita T, Akashi-Tanaka S, et al. Prognostic factors in young Japanese women with breast cancer: prognostic value of age at diagnosis. Jpn J Clin Oncol. 2011;41:180-9.

8. Liu P, Li X, Mittendorf EA, Li J, Du XL, He J, et al. Comparison of clinicopathologic features and survival in young American women aged 18-39 years in different ethnic groups with breast cancer. Br J Cancer. 2013;109:1302-9.

9. Office for National Statistics. Cancer survival in England - adults diagnosed.

https://www.ons.gov.uk/peoplepopulationandcommunity/healthandsocialcare/conditionsanddiseases/datasets/cancersurvivalratescancersurvivalinengl Accessed 12 Jan 2021.

10. da Costa AM, Hashim D, Fregnani JHTG, Weiderpass E. Overall survival and time trends in breast and cervical cancer incidence and mortality in the Regional Health District (RHD) of Barretos, São Paulo, Brazil. BMC Cancer. 2018;18:1079.

11. Instituto Nacional de Câncer. Registros de Câncer de Base Populacional. https://www.inca.gov.br/BasePoplncidencias/Home.action. Accessed 12 Jan 2021.

12. United Nations, Development Programme, Brazil. Atlas do Desenvolvimento Humano no Brasil. http://www.atlasbrasil.org.br/. Accessed 12 Jan 2021.

13. American Joint Committee Breast Cancer. AJCC Cancer Staging Manual Part XI. Eighth edition. Chicago, Illinois: The American College of Surgeons; 2017.

14. Mendes JDV, Cecilio MAM, Osiano VLRL. Boletim Epidemiológico Paulista. Produção de mamografias no SUS do Estado de São Paulo. 2013.

15. Instituto Nacional do Câncer. Diretrizes para a detecção precoce do câncer de mama no Brasil. 2014.

16. Vale DB, Filho CC, Shinzato JY, Spreafico FS, Basu P, Zeferino LC. Downstaging in opportunistic breast cancer screening in Brazil: a temporal trend analysis. BMC Cancer. 2019;19:432.

17. Perry N, Broeders M, de Wolf C, Törnberg S, Holland R, von Karsa L. European guidelines for quality assurance in breast cancer screening and diagnosis. Fourth edition-summary document. Ann Oncol. 2008;19:614-22.

18. Reynoso-Noverón N, Villarreal-Garza C, Soto-Perez-de-Celis E, Arce-Salinas C, Matus-Santos J, Ramírez-Ugalde MT, et al. Clinical and Epidemiological Profile of Breast Cancer in Mexico: Results of the Seguro Popular. J Glob Oncol. 2017;3:757-64.

19. Makdissi FB, Leite FPM, Peres SV, Silva DRM e, Oliveira MM de, Lopez RVM, et al. Breast cancer survival in a brazilian cancer center: a cohort study of 5,095 patients. Mastology. 2019;29:37-46.

20. Fujimoto RHP, Koifman RJ, Silva IF da. Survival rates of breast cancer and predictive factors: a hospital-based study from western Amazon area in Brazil. Cien Saude Colet. 2019;24:261-73.

\section{Figures}




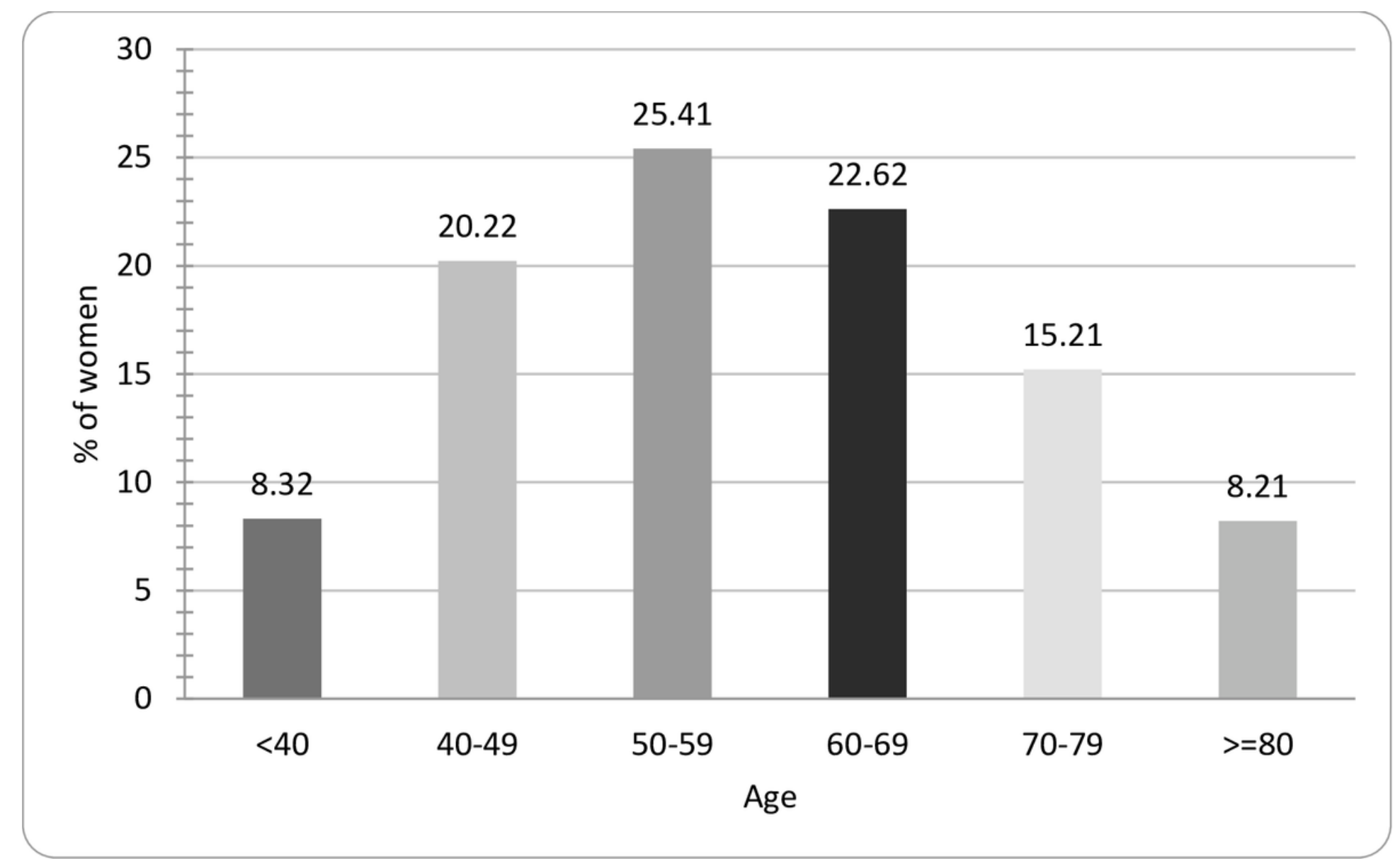

Figure 1

Distribution of women with breast cancer according to the age group at diagnosis $(n=2,715)$. 


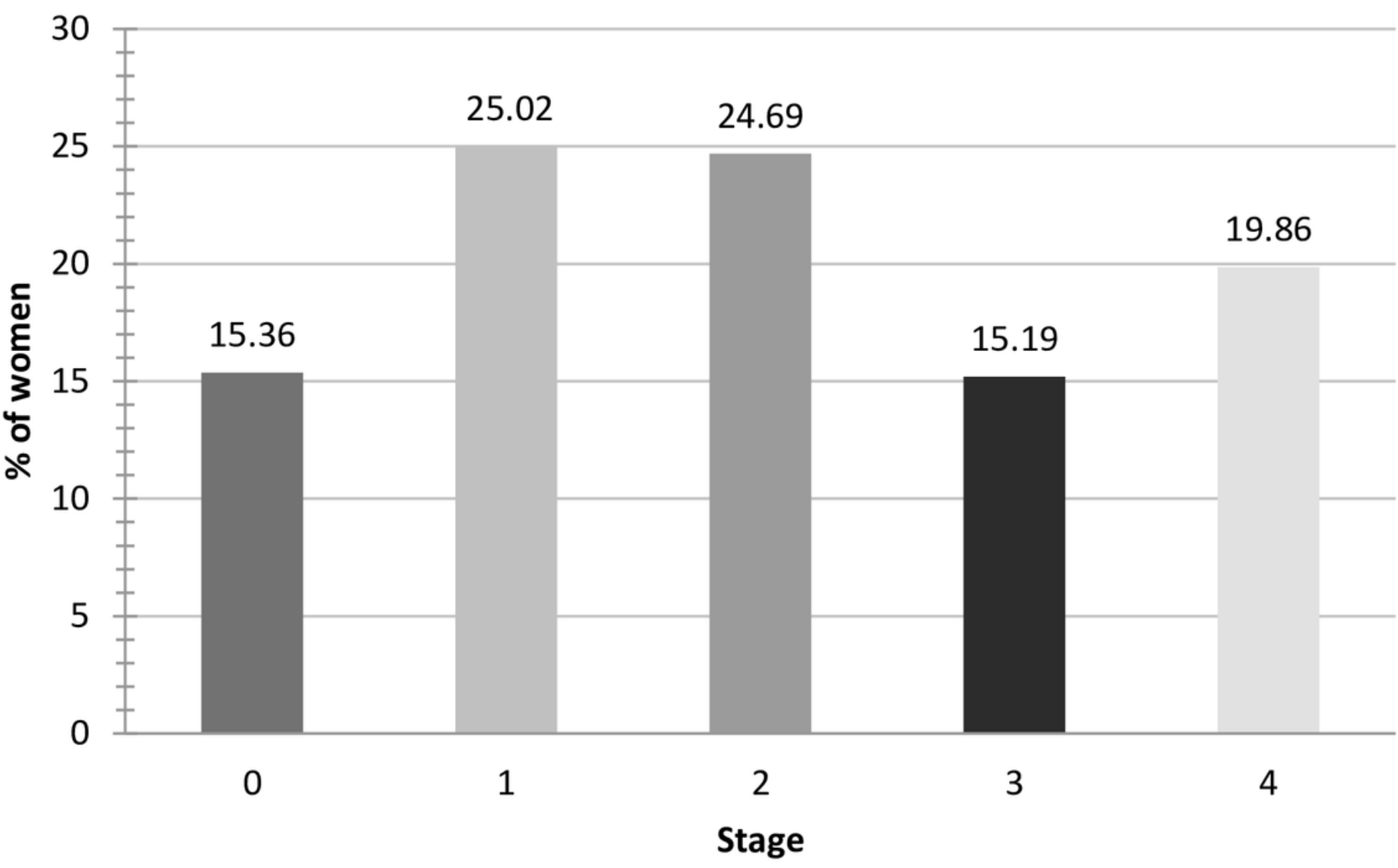

Figure 2

Distribution of women with breast cancer according to the stage at diagnosis $(n=2,054)$.

Survival by age-groups

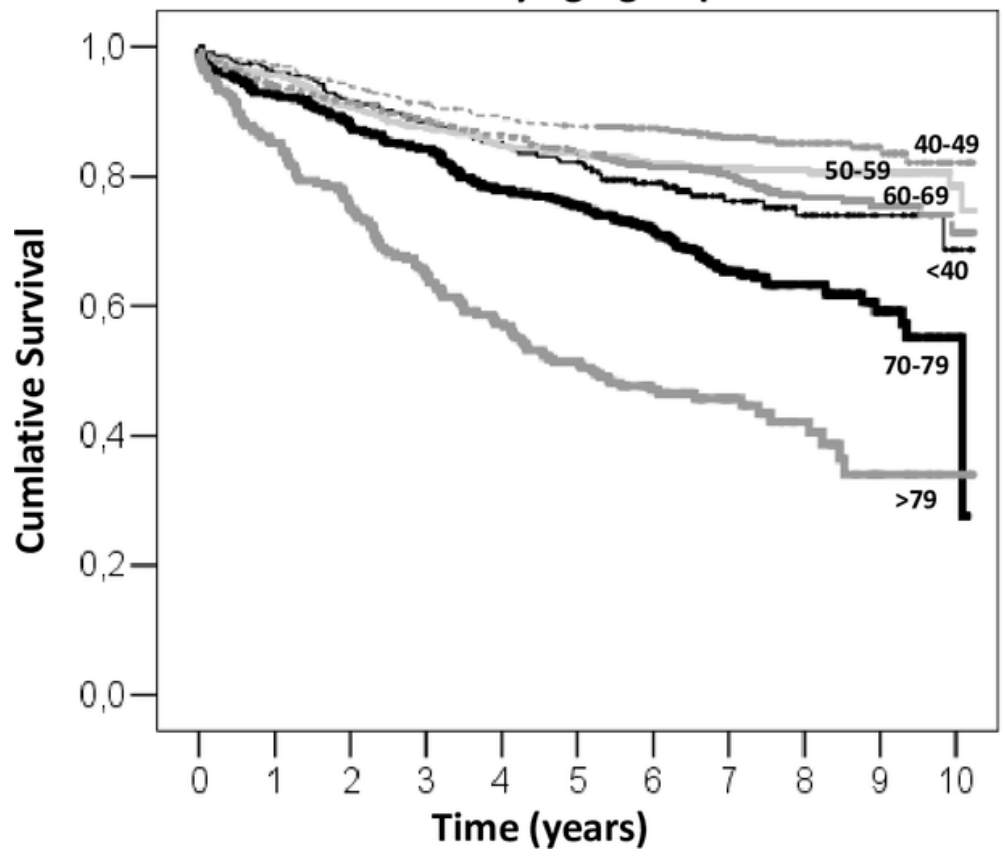

Survival by Stage

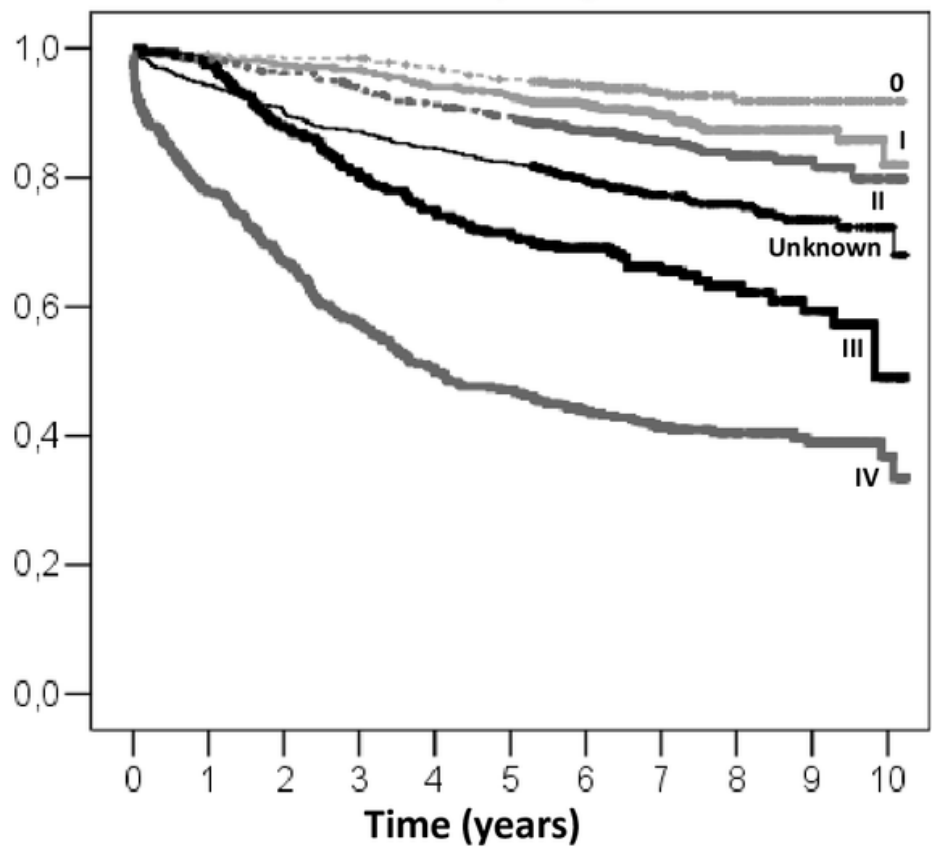

Figure 3

Kaplan-Meyer survival curves for women diagnosed with breast cancer as a function of age and stage $(n=2,715)$. 